\title{
New adjuvants aim to give whooping cough vaccine a boost
}

From 1 January through 9 June of this year, the Washington State Department of Health reported nearly 2,300 cases of pertussis-13 times more than it recorded during those same months in 2011. Public health officials blamed the rash of infections in part on low vaccine uptake in the Northwest, but the existing vaccines against the disease also suffer from serious limitations, prompting scientists around the globe to research better alternatives.

The diphtheria, tetanus and acellular pertussis (DTaP) vaccine given to children in the US and Europe to protect against whooping cough and the related 'Tdap' booster shot both contain purified antigens from the bacterium Bordetella pertussis. These products cause fewer adverse reactions than the older wholecell inoculations that are still in use in the developing world to immunize kids against pertussis, also known as whooping cough. But safety comes at a cost: the existing vaccines provide only up to $85 \%$ protection against the disease, compared with up to $95 \%$ for some whole-cell formulations. Moreover, when a team led by infectious disease specialist David Witt at Kaiser Permanente Medical Center in San Rafael, California, collected background information about the patients who tested positive for pertussis during a massive 2010 outbreak in California, they found that whooping cough rates were no different in vaccinated versus unvaccinated kids between the ages of 8 and 12 (Clin. Infect. Dis., 60, 1730$1735,2012)$. "It's awfully worrisome," says Witt, as it suggests that protection wanes after several years.

Improvements could be forthcoming. One strategy is to develop better adjuvants, as the current choices, aluminum phosphate or aluminum hydroxide, skew the immune system toward an antibody-driven response-a fact that might limit their effectiveness, explains Scott Halperin, director of the Canadian Center for Vaccinology in Halifax, given that antibodies aren't always effective against pathogens that permeate inside cells, as pertussis does. He had his colleagues have developed a new triple-adjuvant formulation that heightens cell-mediated immune responses, killing infected cells. In a mouse study published last year, they reported that a single dose of their formulation boosted levels of circulating IgG2a antibodies-which are indicative of cell-mediated immunity-to match those produced after the mice received the equivalent of two doses of a commercial infant DTaP vaccine (Vaccine 29, 1595-1604, 2011).
Another approach is to design a vaccine specifically for newborns, who are at the highest risk of dying from pertussis. Vaccines don't typically elicit strong immune responses in young babies, but actual infections do. So, Camille Locht, a microbiologist at the University of Lille-North of France, and his colleagues are developing the first live pertussis vaccine, currently called BPZE1, to be given to babies within the first few days of life. "If we give a single nasal drop in the nose of a oneweek-old mouse, just a single administration, the mouse is still protected one year later, which for a mouse is a very long time," Locht explains. And since the bacteria's toxins have been either eliminated or modified, the vaccine should be safe, Locht says.

BPZE1 completed a phase 1 proof-ofconcept trial in adults in 2011, but the group is now optimizing the formulation and plans to initiate another phase 1 trial in 2014. The goal "is not to replace the vaccines that we have," Locht says. But, since babies don't get their first DTaP immunizations until they are two months old and aren't usually well shielded until they have received multiple doses, it would be wonderful "to help infants be protected in the most vulnerable time of their life."

Melinda Wenner Moyer

\section{Accord could make Canadian generics industry a 'rust bucket'}

A trade agreement in negotiations between Canada and the EU is drawing the ire of generic drugmakers, provincial governments and patient advocates over proposals to extend drug patents by several years in Canada, a move that critics say would delay the arrival of generic medicines to market in that country and inflate healthcare costs.

According to Canada's Department of Foreign Affairs and International Trade, Canada imports C $\$ 8.4$ billion ( $\$ 8.2$ billion) of pharmaceutical products from the EU annually, making Canada the fifth largest export market for the continent's drugmakers. The sweeping Comprehensive Economic and Trade Agreement (CETA) could add another \$2.8 billion to the annual bill, according to a report by health economists Paul Grootendorst, from the University of Toronto, and Aidan Hollis, from the University of Calgary (J. Generic Med. $\mathbf{8}, 81-103,2011)$. This cost is largely shouldered by the provincial and territorial governments, which pay for healthcare.

CETA-first proposed in 2009 and subsequently leaked in 2010 — calls on Canada to beef up its intellectual property rights for pharmaceuticals. The proposed changes would add five years to patents for drugs that are unduly bogged down in the regulatory approval process, lengthen the period of time clinical trial data is kept off-limits for use by generics companies from eight years to ten years (or even longer in the case of pediatric drugs) and grant brand-name companies an appeal process to challenge generics companies on their patent compliance.

"It would elevate or harmonize the intellectual property standards in Canada to those of the EU, which is at the forefront of life sciences research," says Declan Hamill, vice president of legal affairs at Rx\&D, an Ottawabased trade group representing brand-name pharmaceutical companies in Canada. "It might change the way the game is played: you give us longer IP [intellectual property], we'll throw some clinical trials your way," adds Grootendorst.

But critics say that the agreement would largely benefit pharmaceutical companies headquartered in Europe. "We will lose investment and become a rust-bucket kind of industry," says Jim Keon, president of the Toronto-based Canadian Generic Pharmaceutical Association (CGPA), who charges that the intellectual property revisions might prompt its members, most of which are international companies with manufacturing facilities in Canada, to go elsewhere.

The recent analysis by Grootendorst and Hollis-commissioned by the CGPA-found that the plan would give patented drugs an exclusive spot on the market for 3.5 years more, on average, than they currently hold. A counteranalysis by Canadian intellectual property lawyers disputes this, but Grootendorst and Hollis question its methodology.

The Canadian government hopes to wrap up the agreement by the end of this year, the country's International Trade Minister Ed Fast said at an economic conference in Montreal last month.

Hannah Hoag 